\title{
Nucleotide-Binding Oligomerization Domain-Like Receptor 3 Inflammasome Inhibition by MCC950 Reduces the Lipopolysaccharide-Induced Interleukin-1ß in Cultured Dispersed Nasal Polyp Cells
}

\author{
Soo Kyoung Park ${ }^{1}$, Rui-Ning $\mathrm{Han}^{2}$, Jun $\mathrm{Xu}^{3}$, Sun Hee Yeon ${ }^{1}$, Sung Bok Lee ${ }^{4}$, \\ Kunho Song, Jenny Byun ${ }^{5}$, Ki Sang Rha', and Yong Min Kim ${ }^{1}$ (iD \\ ${ }^{I}$ Department of Otorhinolaryngology-Head and Neck Surgery, Research Institute for Medical Science, Chungnam National University \\ School of Medicine, Daejeon, Korea; and \\ ${ }^{2}$ Department of Otorhinolaryngology-Head and Neck Surgery, China-Japan Union Hospital, Jilin University, Changchun; and \\ ${ }^{3}$ State Key Laboratory of Respiratory Disease, Department of Otorhinolaryngology-Head and Neck Surgery, First Affiliated Hospital, \\ Guangzhou Medical University, Guangzhou, China; and \\ ${ }^{4}$ Department of Ophthalmology, Chungnam National University School of Medicine, Daejeon; and \\ ${ }^{5}$ Department of Human Environment and Design, Yonsei University College of Social Science, Seoul, Korea
}

\section{MCC950에 의한 Lipopolysaccharide로 유도된 Interleukin-1beta 발현 제어 \\ Dispersed Nasal Polyp Cells에서 Nucleotide-Binding Oligomerization \\ Domain-Like Receptor 3 Inflammasone 억제 가능성에 대한 연구}

박수경 ${ }^{1} \cdot$ 한예녕 $^{2} \cdot$ 허준 $^{3} \cdot$ 연선희 ${ }^{1} \cdot$ 이성복 $^{4} \cdot$ 송근호 $^{1} \cdot$ 변진의 $^{5} \cdot$ 나기상 $^{1} \cdot$ 김용민 $^{1}$

충남대학교 의과대학 이비인후과학교실, ${ }^{1}$ 길림대학교 중화연맹병원 이비인후과학교실, ${ }^{2}$ 광저우대학교 의과대학 이비인후과학교실,

충남대학교 의과대학 안과학교실, ${ }^{4}$ 연세대학교 생활과학대학 생활디자인학과 ${ }^{5}$

\footnotetext{
Received October 8, 2019

Revised December 19, 2019

Accepted January 10, 2020

Address for correspondence

Yong Min Kim, MD, PhD

Department of Otorhinolaryngology-

Head and Neck Surgery,

Chungnam National University

School of Medicine,

282 Munhwa-ro, Jung-gu,

Daejeon 35015, Korea

Tel +82-42-280-7696

Fax $+82-42-253-4059$

E-mail entkym@cnu.ac.kr
}

Background and Objectives The nucleotide-binding oligomerization domain-like receptor (NLRP) 3 is known as a member of the NLR family, and it has been confirmed that the NLRP3 inflammasome is associated with various diseases such as asthma, inflammatory bowel disease, metabolic disorders and multiple sclerosis, as well as other auto-immune and auto-inflammatory diseases. However, the role of NLRP3 in chronic rhinosinusitis with nasal polyps (CRSwNP) has not yet been explored.

Subjects and Method Forty-four specimens of nasal polyps and 25 specimens of uncinate processes were collected from patients with chronic rhinosinusitis with nasal polyps, and 25 specimens of uncinate tissues were collected from patients who underwent other rhino-surgeries. The western blot assay was employed to analyze the expression of NLRP3; interleukin (IL)-1 $\beta$ and IL-17A were detected using immunohistochemistry and real-time polymerase chain reaction. The production of lipopolysaccharide (LPS) induced IL-1 $\beta$ and IL-17A with or without the NLRP3 inflammasome inhibitor (MCC950) was measured using an enzyme linked immunosorbent assay in cultured dispersed nasal polyp cells.

Results NLRP3 showed a high level of expression in nasal polyps than in the control group $(p<0.01)$. The expression of IL-1 $\beta$ and IL-17A was significantly higher in nasal polyps in the CRSwNP group than in the control group $(p<0.05)$. LPS-induced production of IL-1 $\beta$ was significantly suppressed by treatment with the NLRP3 inflammasome inhibitor $(p<0.05)$.

This is an Open Access article distributed under the terms of the Creative Commons Attribution Non-Commercial License (https:/creativecommons.org/licenses/by-nc/4.0) which permits unrestricted non-commercial use, distribution, and reproduction in any medium, provided the original work is properly cited. 
Conclusion The NLRP3 inflammasome plays an essential role in the pathogenesis of CRSwNP, and thus MCC950 can be considered a prospective therapeutic for NLRP3 inflammasome-mediated inflammation in nasal polyps. Our data provide new evidence that IL-17A is involved in inflammasome-associated inflammation in nasal polyps. Korean J Otorhinolaryngol-Head Neck Surg 2020;63(5):206-15

Key Words Inflammasome $\cdot$ Interleukins $\cdot$ Nasal polyps $\cdot$ Sinusitis.

\section{Introduction}

Chronic rhinosinusitis with nasal polyps (CRSwNP) is a chronic inflammatory disease characterized by headaches, olfactory dysfunction, and nasal obstruction and discharge. ${ }^{1)}$ CRSwNP appears to be associated with the helper T cell (Th) 1 , Th2, Th17-biased inflammatory process, but the precise etiology and pathophysiology of CRSwNP remain unknown. ${ }^{2,3)}$

Danger-associated molecular patterns (DAMPs) and pathogen-associated molecular patterns (PAMPs) are reported to be involved in the pathogenesis of CRSwNP. DAMPs and PAMPs are recognized by cytoplasmic pattern recognition receptors, as well as nucleotide-binding oligomerization domain-like receptors (NLRs), toll-like receptors, and retinoic acid-induced gene-like receptors. ${ }^{4}$ NLRs play a critical role in activating and regulating innate immune response. The NLR family pyrin domain - containing 3 (NLRP3)-is a known member of the NLR family, and could combine with an apoptosis-associated speck-like protein containing a CARD and pro-caspase-1 to make up the NLRP3 inflammasome. ${ }^{5)}$ And NLRP3 inflammasome acts as a pattern recognition receptor and triggers caspase- 1 activation and IL-1 $\beta$ and IL-18 maturation. ${ }^{6,7)}$ In a previous study, a two-signal model was suggested for NLRP3 inflammasome activation. The first signal, a priming step, is produced by microbial or endogenous molecules that induce NLRP3 and pro-IL-1 $\beta$ expression through NF- $\kappa$ B activation. The second signal is triggered once again by pore-forming toxins, viral RNA, adenosine triphosphate (ATP), or particulate matter, which then activates the NLRP3 inflammasome. ${ }^{89}$

Recent studies have revealed that the NLRP3 inflammasome plays an important role in various diseases including asthma, obstructive pulmonary disease (COPD), inflammatory bowel disease, metabolic disorders and multiple sclerosis, in addition to other auto-immune and auto-inflammatory diseases. ${ }^{10-12)}$ However, the role of NLRP3 in CRSwNP remains uncertain. The aim of this study was to evaluate whether the expression of NLRP3 and IL-1 $\beta$ is higher in the tissues of CRSwNP pa- tients than in those of control patients, and to determine whether IL-1 $\beta$ is induced through the formation of the NLRP3 inflammasome in dispersed nasal polyp cells (DNPCs). Furthermore, the authors aimed to explore the expression of IL-17A involved in NLRP3 inflammasome associated the pathogenesis of nasal polyps.

\section{Subjects and Method}

\section{Patients and tissue preparation}

After this study was approved by the Institutional Review Board of Chungnam National University Hospital (2015-12027), a total of 49 outpatients visiting the Department of Otorhinolaryngology at Chungnam National University Hospital (South Korea) between January 2016 and January 2017 were included in the study. A written informed consent was obtained from all patients before enrollment. Among these patients, 44 had CRSwNP; while the other 25 subjects had undergone other rhino-surgeries (e.g. dacriocystostomy or endoscopic orbital decompression surgery), and were enrolled as control subjects. Uncinate tissues (UT) were obtained from 15 patients with CRSwNP and 25 control subjects. Polyp tissues were obtained from the NP in patients with CRSwNP. NP

Table 1. Patient characteristics

\begin{tabular}{lllll}
\hline \multirow{2}{*}{ Group } & \multicolumn{2}{c}{ Controls } & & \multicolumn{2}{c}{ CRSwNP } \\
\cline { 2 - 3 } \cline { 5 - 5 } & Uncinate & & Uncinate & Nasal polyp \\
\hline Total of subjects, $\mathrm{n}$ & 25 & 25 & 44 \\
Sex, male, $\mathrm{n}(\%)$ & $12(48)$ & $12(48)$ & $29(65.9)$ \\
Age, median (IQR), year & $42(20.2)$ & $45(17.2)$ & $52(14.8)$ \\
Allergic rhinitis, n (\%) & $5(20)$ & $8(32)$ & $17(38.3)$ \\
Bronchial asthma, n (\%) & $0(0)$ & $3(12)$ & $7(15)$ \\
Atopic dermatitis, n (\%) & $0(0)$ & $0(0)$ & $1(2)$ \\
Aspirin intolerence, n (\%) & $0(0)$ & $0(0)$ & $0(0)$ \\
Lund-Mackay CT score, & $0(0)^{*+}$ & $12.4(5.4)$ & $16.5(6.8)$
\end{tabular}
median (IQR)

$* p<0.05$ compared with Uncinate of CRSWNP, ${ }^{t} p<0.05$ compared with nasal polyp of CRSWNP. CRSWNP: chronic rhinosinusitis, IQR: interquartilerange 
tissues from 5 patients were used for culture of DNPCs, and those from 10 patients underwent flow cytometric analysis.

Diagnosis of sinus disease was based on patient history, clinical examination, nasal endoscopy, and computed tomography of the paranasal sinuses (as detailed by the guidelines contained in EPOS 2012: European position paper on rhinosinusitis and NPs 2012). ${ }^{1)}$ Exclusion criteria included those who used oral or nasal corticosteroids or medications (e.g., antibiotics or anti-leukotrienes) 4 weeks prior to sample collection, suffered from recent upper respiratory tract infections, or underwent surgical revision. Table 1 contains details of notable patient characteristics. The diagnosis of asthma, atopic dermatitis and aspirin intolerance was referred to a respiratory physicians. There was no significant difference between the 3 groups with respect to age, gender, comorbidity of allergic rhinitis, atopic dermatitis, or bronchial asthma.

\section{DNPC culture}

As described previously, enzymatic digestion methods were used to obtain DNPCs from NP patients. NP tissue was briefly rinsed two times with phosphate-buffered saline (PBS) and removed of bone fragments. The NPs were chopped with scissors and incubated for $2 \mathrm{~h}$ at $37^{\circ} \mathrm{C}$ in DMEM containing $2.0 \mathrm{mg} / \mathrm{mL}$ protease, $1.5 \mathrm{mg} / \mathrm{mL}$ collagenase, $0.75 \mathrm{mg} / \mathrm{mL}$ hyaluronidase, and $0.05 \mathrm{mg} / \mathrm{mL}$ DNase. The separated cells were once again filtered with a pore size of $70 \mu \mathrm{m}$ (SPL, Pocheon, Republic of Korea). It was washed 3 more times with a complete growth medium, RPMI 1640 (HyClone, Logan, UT, USA) accompanied by $10 \%$ fetal bovine serum, $100 \mathrm{IU} / \mathrm{mL}$ streptomycin, $100 \mathrm{IU} / \mathrm{mL}$ penicillin, and $1 \%$ L-glutamine.

In order to remove red blood cells, they were suspended in an ACK Lysis Buffer (Lonza, Walkersville, MD, USA) and washed twice with PBS. Then the cell pellet was suspended in the complete growth medium. A concentration of $3 \times 10^{6}$ cells/well was used. The cells were treated with lipopolysaccharides (LPS) alone or co-treated with LPS, ATP, and MCC950 (a specific inhibitor of NLRP3).

The cytokine protein levels in the cultured supernatant or cells were detected by enzyme linked immunosorbent assay (ELISA) and western blotting respectively.

\section{Immunohistochemical assays}

All biopsy specimens were fixed in 4\% paraformaldehyde embedded with paraffin and sliced into $4 \mu \mathrm{m}$ thickness. Antigen retrieval was done using De-cloaking Chamber (Biocare Medical, Concord, CA, USA) in a pressure-cooker for one whistle after which the slides were cooled for 15-20 min. We used 5\% goat serum blocking buffer (Vector, Burlingame, $\mathrm{CA}$, USA) to prevent nonspecific binging. IL-1 $\beta$ antibody and IL-17A antibody (cell signaling) were incubated at $4^{\circ} \mathrm{C}$ overnight. The slide was rinsed three times with PBS.

The sections were rinsed three times with PBS and then incubated for 2 hours at room temperature with biotinylated rabbit anti-goat IgG (Vector) as a secondary antibody. After further washing, the slides were incubated in horseradish peroxidase streptavidin (Vector) before being stained with 3,3'-Diaminobenzidine tetrahydrochloride hydrate (Sigma-Aldrich, St. Louis, MO, USA). To visualize tissue structure, the sections were counterstained with hematoxylin using a commercially available kit (Vector). After rinsing with PBS, the samples were mounted using Permount ${ }^{\mathrm{TM}}$ Mounting Medium (Fisher Chemical, Fair Lawn, NJ, USA). The slides were then observed under an optical microscope (Olympus, Tokyo, Japan). Positive cells were counted per high-powered field $(\mathrm{HPF}, \times 400)$ at three different sites in the tissue. Mean values with range were calculated as well.

\section{Flow cytometric assay}

DNPCs were cultured in RPMI 1640 containing 10\% FBS and $1 \%$ penicillin/streptomycin. Immunostaining was performedusing fluorochrome-conjugated antibodies (Miltenyi Biotec, Bergisch Gladbach, Germany) which is suitable for various cell surface markers in identifying cellular components of DNPCs. 7-Aminoactinomycin D (7-AAD) (Sigma-Aldrich) was also used to detect viable cells. These cells were incubated with NLRP3, CD68, CD19, Vimentin, CD11c, CD193, CD3, CD127, CD117, and IL17A (eBioscience, San Diego, CA, USA) for 10 minutes at $4^{\circ} \mathrm{C}$ in the dark.

After washing the cells two times with PBS, they were stained with $7-\mathrm{AAD}$ in the dark for 10 minutes at $4^{\circ} \mathrm{C}$. The cells were washed and resuspended in 1\% paraformaldehyde (Biosesang, Seongnam, Republic of Korea) for FACS analysis.

Multi-parameter flow cytometry was performed using a BD LSR II instrument (BD Biosciences, San Jose, CA, USA) and FACS Diva software (BD Biosciences).

\section{Cytotoxicity assay}

To determine the cell cytotoxicity of LPS, ATP, and MCC950, the MTT [3-(4,5-dimethylthiazol-2-yl)-2,5-diphenyl-tetrazolium bromide, Sigma-Aldrich] test was performed. In brief, DNPCs were inoculated in the 96-well plate, 50000 cells per well. 24 hours after incubation, DNPCs were treated with dif- 
ferent doses of LPS, ATP and MCC950. After 24 hours, $10 \mu \mathrm{L}$ of MTT solution ( $5 \mathrm{mg} / \mathrm{mL}$ ) was added to the cells for 4 hours, and then dimethylsulfoxide was added. The optical density of each well was measured at $490 \mathrm{~nm}$ with microplate reader Filter Max F5 (Molecular Devices, San Jose, CA, USA). All assays were performed in triplicate.

\section{Real-time polymerase chain reaction}

Total RNA was extracted by the TRIzol ${ }^{\mathrm{TM}}$ reagent (Invitrogen, Carlsbad, CA, USA) and then reversely transcribed with AccuPower $^{\mathrm{TM}}$ RT PreMix (Bioneer, Daejeon, Republic of Korea). Quantitative realtime reverse transcription-polymerase chain reaction (PCR) was performed to calculate gene expressions with a CFX Connect ${ }^{\mathrm{TM}}$ Real-Time PCR Detection System (Bio-Rad Laboratories, Hercules, CA, USA) and PowerUp ${ }^{\mathrm{TM}}$ SYBR ${ }^{\circledR}$ Green Master Mix (Applied Biosystems, Carlsbad, CA, USA), with glyceraldehyde-3-phosphate dehydrogenase (GAPDH) as the internal reference. PCR was performed by the following primers: human (IL-1 $\beta$ ) (sense sequence: AAACAGATGAAGTGCTCCTTCCAGG and antisense sequence: TGG-AGAACACCACTTGTTGCTCCA); human (IL17A) (sense sequence: CCCCATCCAGCAAGAGATCC and antisense sequence: CCCACGGACACCAGTATCTT); GAPDH (sense sequence: AAA-TCAAGTGGGGCGATGCT and antisense sequence: CAA-ATGAGCCCCAGCCTTCT).

We calculated the $\mathrm{Ct}$ value, and the relative quantitation values were once again calculated by the $2-\Delta \Delta \mathrm{Ct}$ method.

\section{Western blot analysis}

Proteins from patient tissues were extracted with sterilized scissors and RIPA buffer (Cell Signaling Technology, Danvers, MA, USA) which contains protease inhibitor. Total protein was determined using the Bradford assay (Cell Signaling Technology). $50 \mu \mathrm{g}$ of extracted protein was electrophoresed in $10 \%$ sodium dodecyl sulfate-polyacrylamide gels and then transferred to polyvinylidene difluoride membranes (Millipore, Bilerica, MA, USA).

Antibody were diluted in TBST (20 mM Tris-base; $137 \mathrm{mM}$ $\mathrm{NaCl}, \mathrm{pH} 7.6$; and $0.05 \%$ Tween 20 ) containing 5\% non-fat milk and incubated overnight with Human IL-17A antibody (R\&D Systems, Minneapolis, MN, USA), NLRP3 antibody (cell signaling), $\beta$-actin antibody (Cell Signaling) and GAPDH antibody (Cell Signaling) as primary antibodies.

Membranes were washed three times with TBST, and incubated with horseradish peroxidase (HRP)-conjugated secondary antibodies. After washing three times with TBST, We used the Chemilminescence with Amersham ECL plus western blotting detection system (GE Heathcare, Chicago, IL, USA).

\section{ELISA}

Protein levels of IL-1 $\beta$ in the supernatants from cultured DNPCs were measured using an ELISA kit (BD Biosciences) according to manufacturer's instructions. The lower detection limit of this kit is $2.7 \mathrm{pg} / \mathrm{mL}$

\section{Statistical analysis}

Statistical analyses were performed with SPSS 22 (version 22.0, IBM Corp., Armonk, NY, USA) and GraphPad Prism 6 (version 6.01, GraphPad Software, La Jolla, CA, USA). To reveal continuous variables, results were shown as mean with standard error of mean (SEM). D'Agostino-Pearson omnibus normality test, Mann-Whitney U test, Kruskal-Wallis tests (2-tailed), and two-way ANOVA with Scheffe post hoc test were used for the normality test, comparisons of the two groups, and multiple testing, respectively. Spearman's rank correlation coefficient was used to determine variable relationships. A $p$ value less than 0.05 was considered statistically significant.

\section{Results}

\section{Expression of NLRP3 is higher in nasal polyps of CRSwNP patients than the in the mucosa of the control group}

Expression of NLRP3 inflammasome in nasal tissues was determined by western blot assay, which was significantly elevated in nasal polyps of the CRSwNP group compared to the control group and UT of the CRSwNP group $(p<0.001 ; p<$ 0.05). There was no significant difference in NLRP3 expression of UT between the control group and the CRSwNP group (Fig. 1A and B). mRNA expression of NLRP3 also showed a similar pattern with the results of western blot analysis, and NLRP3 mRNA levels were significantly elevated in nasal polyps compared with UT of the control group and CRSwNP groups $(p<0.01)$ (Fig. 1C).

We then investigated which cells could express the NLRP3 in nasal polyp tissues using flow cytometry. Various cells, including epithelial cells, macrophages, B cells, fibroblasts, dendritic cells and eosinophils, expressed the NLRP3 molecule. However, the CD3-positive T cells did not express the NLRP3. Our study data showed that the epithelial cells, macrophages, fibroblast and the dendritic cells were the major cells that ex- 

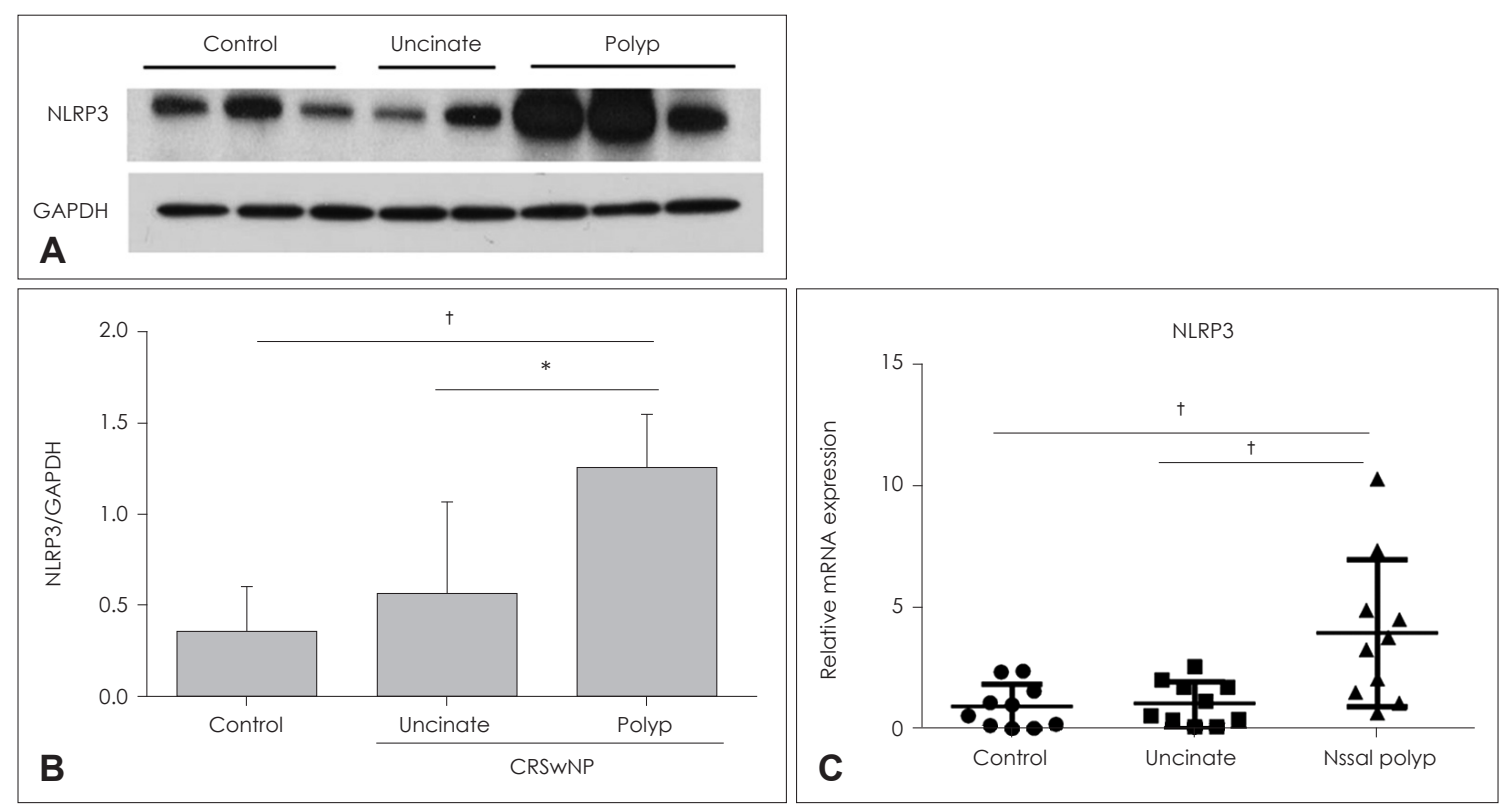

Fig. 1. Expression of NLRP3 in nasal tissues. NLRP3 inflammasome expression was significantly elevated in the nasal polyps of the CRSwNP group compared with the controls and uncinate tissues of the CRSwNP group (A, B). The mRNA expression of NLRP3 was analyzed by quantitative real-time polymerase chain reaction (C). Results are expressed as the mean concentration of triplicate samples. Data are expressed as means \pm SEM. ${ }^{*} p<0.05,+p<0.01$. NLRP3: nucleotide-binding oligomerization domain-like receptor 3 , CRSwNP: chronic rhinosinusitis with nasal polyps.

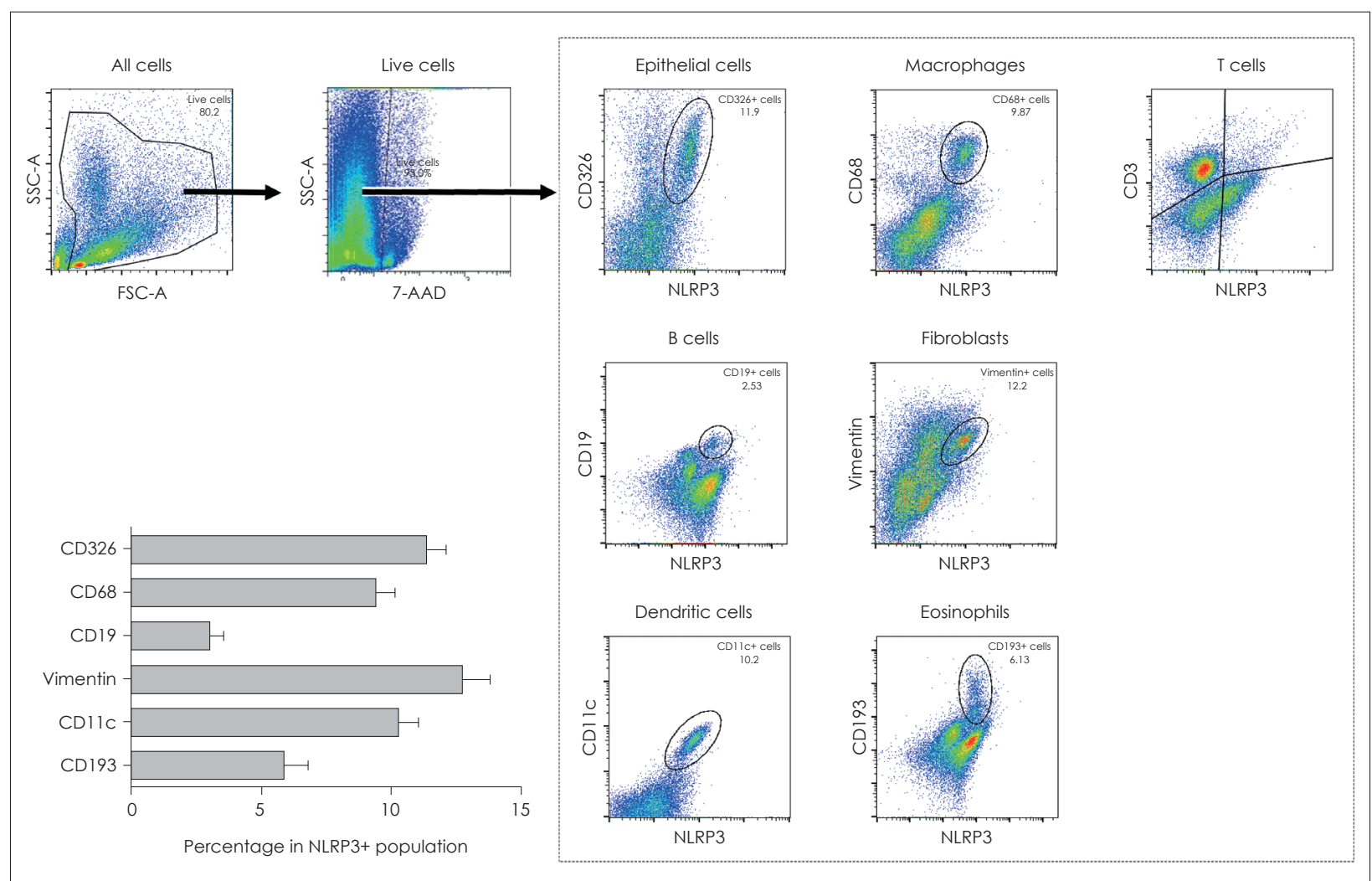

Fig. 2. FACS analysis showed that various cells were the origin of NLRP+ expressing cells in DNPCs. Representative images and quantification data regarding the cellular origin of NLRP3 in DNPCs is shown $(n=10)$. The NLRP3+ population was gated after the gating of the main population in DNPCs. Various cellular markers including CD326 for epithelial cell, CD68 for macrophage, CD19 for B-cell, vimentin for fibroblast, CD11c for dendritic cell and CD193 for eosinophil were then used to identify the cells expressing NLRP3. NLRP: nucleotide-binding oligomerization domain-like receptor, DNPCs: dispersed nasal polyp cells. 
pressed NLRP3 (Fig. 2).

\section{Expression of IL-1ß is higher in nasal polyps than in UT}

Immunohistochemistry revealed that IL- $1 \beta$ was expressed not only in nasal epithelial cells but also in various inflammatory cells of sub-epithelial area. Compared with UT in the control and CRSwNP groups, the number of IL-1 $\beta$-positive cells was significantly elevated in nasal polyps of the CRSwNP group ( $p<0.001$ and $p<0.05$, respectively) (Fig. 3A-E). mRNA expression of IL-1 $\beta$ also showed a similar pattern with the results of immunohistochemistry, and IL-1 $\beta$ mRNA levels were significantly elevated in nasal polyps compared with UT of the control group and CRSwNP groups $(p<0.05)$ (Fig. $3 \mathrm{~F})$. As shown in Fig. $3 \mathrm{G}$, there was strong positive correlation between the expression of IL-1 $\beta$ mRNA levels in nasal polyp tissues and Lund-Mackay CT score of patients.

\section{IL-1 $\beta$ expression is mediated by NLRP3 inflamma- some in nasal polyps}

It is well known that NLRP3 inflammasome is induced by
LPS and ATP, and that MCC950 blocks formation of the NLRP3 inflammasome. In DNPCs, LPS with/without ATP, or MCC950 did not affect cell viability using MTT assay (Fig. $4 \mathrm{~A}$ and $\mathrm{B})$.

The production of IL-1 $\beta$ was increased dose-dependently by stimulation of LPS with ATP (Fig. 4C). In addition, LPSinduced IL-1 $\beta$ production was inhibited by treatment with MCC950 (Fig. 4D).

\section{IL-1 $\beta$-mediated IL-17A expression in nasal polyps}

As regards to Asian nasal polyps, it is well-known that IL17A plays an important role in the pathogenesis of nasal polyps by triggering various inflammatory responses. ${ }^{13-15)}$

IL-17A-positive cells were observed in both epithelial cells and sub-epithelial cells using immunohistochemistry (Fig. 5A-D). IL-17A expression was higher in nasal polyps compared with UT taken from the control and CRSwNP groups using immunohistochemistry $(p<0.0001)$ (Fig. 5E) and RT-PCR $(p<$ 0.05) (Fig. 5F).

We contemplated whether the expression of IL-17A was
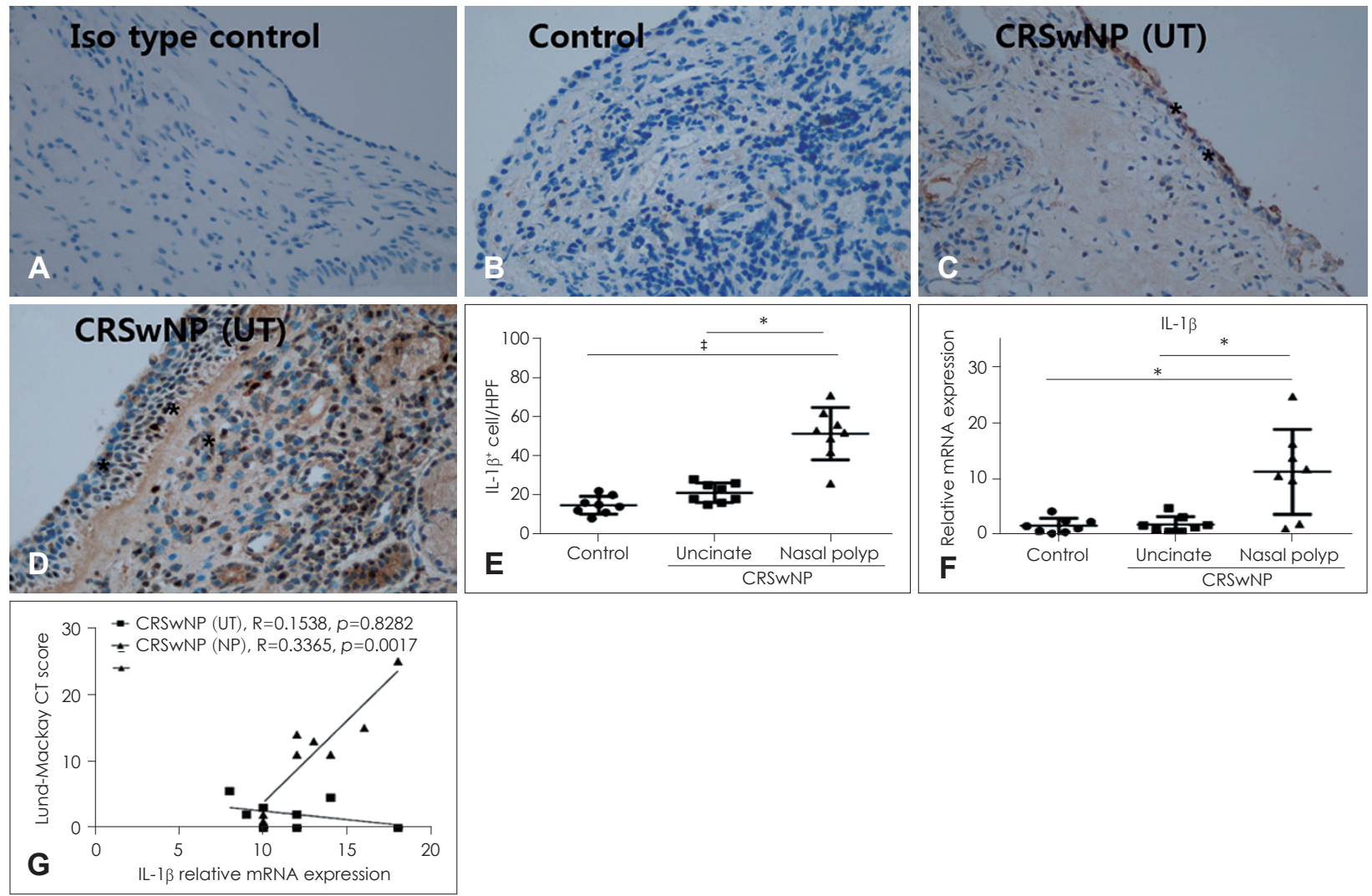

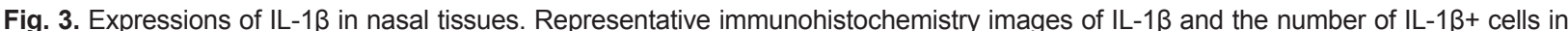
the nasal tissues from different group are shown (indicated by asterisks) (A-E) ( $\times 400)$. The mRNA expression of IL-1 $\beta$ was analyzed by quantitative real-time polymerase chain reaction $(\mathrm{F})$. The correlation between expression of IL-1 $\beta$ mRNA levels and Lund-Mackay CT score of patients $(G)$. Results are expressed as the mean concentration of triplicate samples. ${ }^{*} p<0.05, \pm p<0.001$. CRSwNP: chronic rhinosinusitis with nasal polyps, UT: Uncinate tissues. 
involved in inflammasome-associated inflammation in nasal polyps. Therefore, DNPCs were treated with IL-1 $\beta$, and the production of IL-17A was increased in a dose-dependent manner, rising significantly at $50 \mathrm{ng} / \mathrm{mL}$ compared to 10 and 25 $\mathrm{ng} / \mathrm{mL}$ of rIL-1 $\beta(p<0.001)$ (Fig. $5 \mathrm{G})$. The mRNA production of IL-17A was increased by stimulation of LPS with ATP. Additionally, LPS-induced IL-17A production was inhibited by treatment with $10 \mu \mathrm{M}$ MCC950, but was not statistically significant (Fig. 5H).

\section{Discussion}

Despite recent increasing interest in NLRP inflammasomes, little is understood about the role of inflammasome activation in airway of patients with lower airway diseases. Only a few number of cases discussing patients with CRS have been reported to date. This study examined the characteriza- tion of NLRP3 expression during CRS pathogenesis. The authors found that the expression of NLRP3 was significantly increased in the nasal polyp group compared to the control group, and considered it to be a chronic inflammatory disease. ${ }^{16)}$ characterized by formation of Th-cell-dominated cytokines which the cell surface may carry large amounts of NLRs in response to the endogenous dangerous signals caused by the inflammation itself. $^{17)}$ In previous studies, NLRP3 was also observed to be involved in the development and progression of a number of inflammatory diseases in patients with allergic rhinitis, COPD, and inflammatory bowel disease. ${ }^{18-20)}$ Also, though it is well documented that NLRP3 is mainly expressed in macrophages, ${ }^{21,22)}$ we detected NLRP3 expression in nasal tissue in several types of cells, including macrophages, fibroblasts, dendritic cells, and epithelial cells.

Emerging evidence suggests that activation of NLRP3 inflammasome leads to maturation and secretion of IL-1 $\beta$, and
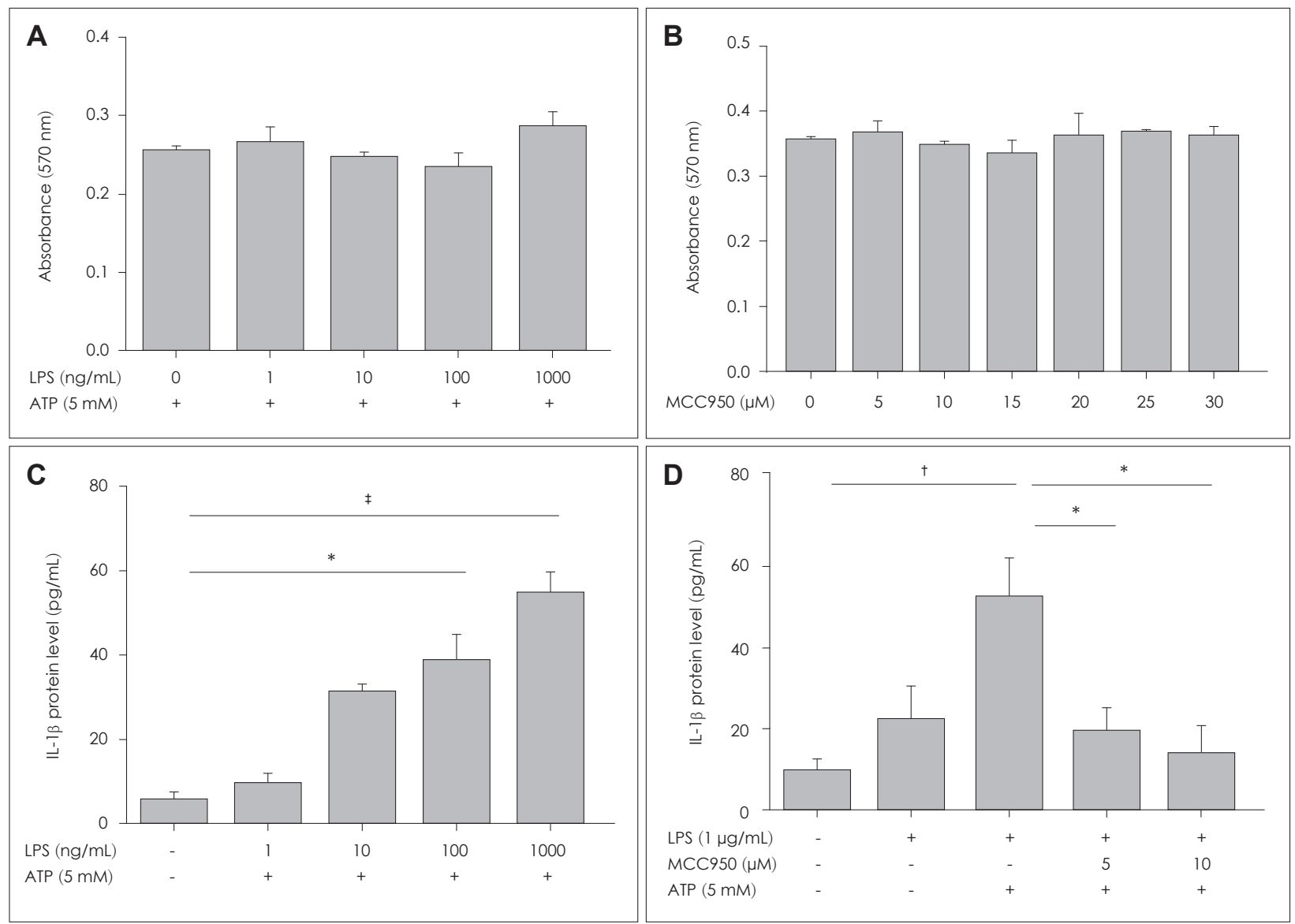

Fig. 4. IL-1 $1 \beta$ expression is mediated by NLRP3 inflammasome in nasal polyps. Cytotoxicity assay for LPS and MCC950 in DNPCs. The MTT assay was performed after 72 hours of treatment with LPS and MCC950 in DNPCs (A, B). The production of IL-1 13 in DNPCs supernatants increased with ATP and increasing LPS concentration (C). Expression of IL-1 $\beta$ in DNPCs supernatants decreased with MCC950 compared with LPS+ATP group (D) $(C: n=3, D: n=3)$. The protein levels of IL-1 $\beta$ in the supernatant were measured by enzyme linked immunosorbent assay. Results are expressed as the mean concentration of triplicate samples. Data are expressed as means \pm SEM. ${ }^{*} p<0.05, t p<0.01, \neq p<0.001$. LPS: lipopolysaccharide, ATP: adenosine triphosphate, NLRP3: nucleotide-binding oligomerization domain-like receptor 3, DNPCs: dispersed nasal polyp cells. 

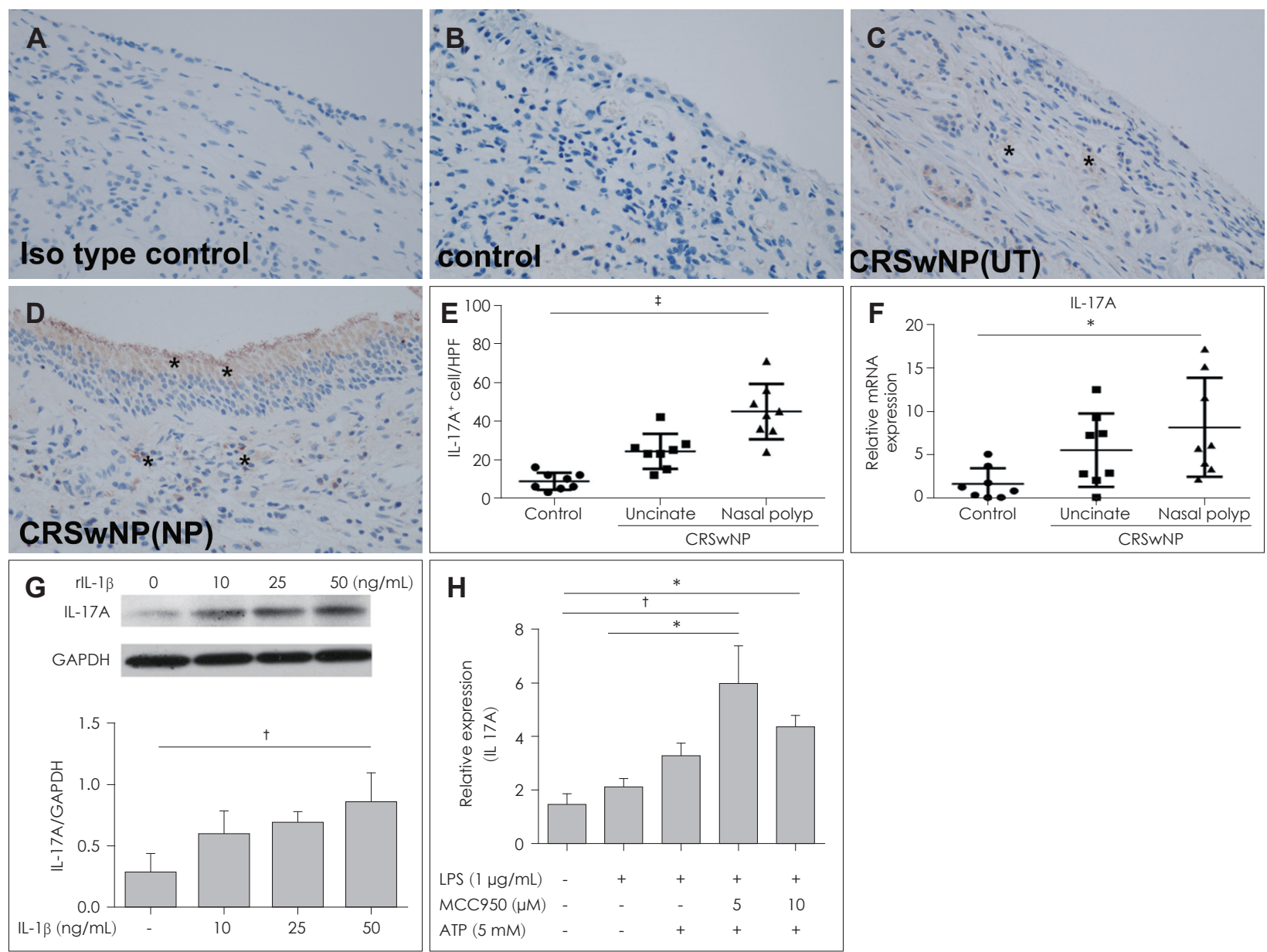

Fig. 5. IL-1ß-mediated IL-17A expression in nasal polyps. Representative immunohistochemistry images of IL-17A and the number of $\mathrm{IL}-17+$ cells in the nasal tissues from different group are shown (indicated by asterisks) (A-E) ( $\times 400)$. The mRNA expression of IL-17 was analyzed by quantitative RT-PCR $(F)$. Protein expression level of IL-17A was increased in a dose dependent manner of rIL-1 $1 \beta$. The protein levels of IL-17A in the supernatant were measured by enzyme linked immunosorbent assay (G). The mRNA production of IL-17A in dispersed nasal polyp cells supernatants increased with APT and LPS. The mRNA levels of IL-17A in the supernatant were measured by RT-PCR $(H)(G: n=5, F: n=5)$. Results are expressed as the mean concentration of triplicate samples. Data are expressed as means \pm SEM. ${ }^{*} p<0.05,+p<0.01, \neq p<0.001$. CRSwNP: chronic rhinosinusitis with nasal polyps, UT: Uncinate tissues, RT-PCR: real-time polymerase chain reaction.

that NLRP3 inflammasome is the best-characterized inflammasome so far, acting as a molecular platform for IL- $1 \beta$ secretion. ${ }^{6,23)}$ The immunohistochemical examination of the present study demonstrated local expression of IL-1 $1 \beta$ in the nasal polyp group. Extending this, we found an increase in protein levels of IL-1 $\beta$ in patients with CRS compared to the control group.

NLRP3 inflammasome was initially known to be activated by ATP and certain bacterial toxins ${ }^{24)}$ and previous studies have shown that ATP can be considered as a NLRP3 agonist, which activates NLRP3 inflammasome by activating the P2X7 ion channel to induce $\mathrm{K}+\mathrm{efflux}^{25)}$ Many studies have shown that LPS is involved in the activation of NLRP3 inflammasome, ${ }^{26-28)}$ and that LPS and the occurrence of nasal polyps are closely related to the development other inflammatory diseases. ${ }^{21,29)}$ MCC950 is a diarylsulfonylurea compound. In the first study of it, MCC950 was considered an inhibitor of IL-1 $\beta$, but its effect on inflammasome activation is unclear. In recent years, MCC950 has been reported to inhibit activation of NLRP3 inflammasome. ${ }^{30)}$ In this study, the expression of pro-IL-1 $\beta$ was significantly up-regulated, while IL-1 $\beta$ was only slightly increased when DNPCs were treated with LPS alone. The expression of IL-1 $\beta$ was significantly increased when LPS and ATP were administered simultaneously. Also, it was observed that MCC950 effectively inhibited the production of LPS-induced IL-1 $\beta$ in nasal polyps, indicating that the effect of MCC950 on NLRP3 is to inhibit the activation phase of NLRP3.

Next, we questioned the role of IL-1 $\beta$ in the pathogenesis of nasal polyps. According to the former study, it is known that IL-17A triggers various inflammatory responses in Asian nasal polyps. ${ }^{21)}$ Therefore, we investigated the expression of IL- 
$17 \mathrm{~A}$ involved in inflammasome-associated inflammation in nasal polyps. This study revealed that IL-1 $\beta$ could induce the production of IL-17A, and also indicated that IL-17A is involved in inflammasome-associated inflammation in nasal polyps.

We further evaluated the possibility that LPS would induce IL-17A production, as well as possible mechanism, adopting the MCC950 addition. In present study, IL-17A mRNA expression level was significantly induced by LPS and ATP treatment. LPS induced IL-17A production was partially suppressed by $10 \mu \mathrm{M}$ of MCC950, but was not statistically significant.

This study shows that CRSwNP patients have an augmented expression of NLRP3 inflammasome and an increased release of IL-1 $\beta$ and IL-17A protein. Although a previous study have shown that NLRP3 inflammasome played a pivotal role in the pathogenesis of CRSwNP, especially in Eosinophilic Chronic sinusitis with nasal polyps (ECRSwNP), this is the first study to implicate the association of IL-1 $\beta$ with IL-17A in patients with CRSwNP. ${ }^{31)}$ However, there are a few limitations to the present study. As the research was conducted on a relatively small sample, it will be necessary to conduct a multicenter study involving a larger patient group to clarify this finding in the future. We also studied the role of only NLRP3 in CRSwNP which might have unduly influenced the data.

In this study, we found that the expression of NLRP3 and IL-1 $\beta$ protein levels were significantly increased in patients with CRS compared to the control group. Also, MCC950 effectively inhibited the production of LPS-induced IL- $1 \beta$ in nasal polyps group compared to the control group. We have conclude that NLRP3 inflammasome plays an important role in the pathogenesis of CRSwNP, and IL-1 $\beta$ and IL-17 are involved in this signaling pathway. Also, NLRP3 signaling pathway was augmented by LPS but partially suppressed by MCC950. These observations suggest that MCC950 is a potential therapeutic for NLRP3 inflammasome mediated inflammation in nasal polyps. Furthermore, our data may provide new evidence to support the hypothesis that IL-17A is involved in inflammasomeassociated inflammation in nasal polyps.

\section{Acknowledgments}

We would like to thank the study participants and all of the joint research workers. Finally, we would like to thank the patients who provided samples for this study.

This work was funded by research fund of Chungnam National University 2018.

\section{Author Contribution}

Conceptualization: Yong Min Kim, Soo Kyoung Park. Data curation: Rui-Ning Han. Formal analysis: Jun Xu. Investigation: Soo Kyoung Park, Yong Min Kim. Methodology: Sun Hee Yeon. Project administration: Ki Sang Rha. Resources: Sung Bok Lee. Software: Jun Xu. Supervision: Yong Min Kim. Validation: Kunho Song. Visualization: Byun Jenny. Writing — original draft: Soo Kyoung Park. Writing — review \& editing: Soo Kyoung Park.

\section{ORCIDs}

Yong Min Kim

https://orcid.org/0000-0001-5414-8332

Soo Kyoung Park

https://orcid.org/0000-0002-5163-536X

\section{REFERENCES}

1) Fokkens WJ, Lund VJ, Mullol J, Bachert C, Alobid I, Baroody F, et al. European position paper on rhinosinusitis and nasal polyps 2012. Rhinol Suppl 2012;23:3 p preceding table of contents, 1-298.

2) Cao PP, Li HB, Wang BF, Wang SB, You XJ, Cui YH, et al. Distinct immunopathologic characteristics of various types of chronic rhinosinusitis in adult Chinese. J Allergy Clin Immunol 2009;124(3): 478-84.

3) Makihara S, Okano M, Fujiwara T, Kariya S, Noda Y, Higaki T, et al. Regulation and characterization of IL-17A expression in patients with chronic rhinosinusitis and its relationship with eosinophilic inflammation. J Allergy Clin Immunol 2010;126(2):397-400.

4) Bachert C, Holtappels G. Pathophysiology of chronic rhinosinusitis, pharmaceutical therapy options. GMS Curr Top Otorhinolaryngol Head Neck Surg 2015;14:Doc09.

5) Davis BK, Wen H, Ting JP. The inflammasome NLRs in immunity, inflammation, and associated diseases. Annu Rev Immunol 2011; 29:707-35.

6) De Nardo D, Latz E. NLRP3 inflammasomes link inflammation and metabolic disease. Trends Immunol 2011;32(8):373-9.

7) Martinon F, Burns K, Tschopp J. The inflammasome: A molecular platform triggering activation of inflammatory caspases and processing of proIL-beta. Mol Cell 2002;10(2):417-26.

8) Hornung V, Latz E. Critical functions of priming and lysosomal damage for NLRP3 activation. Eur J Immunol 2010;40(3):620-3.

9) Tschopp J, Schroder K. NLRP3 inflammasome activation: The convergence of multiple signalling pathways on ROS production? Nat Rev Immunol 2010;10(3):210-5.

10) Ozaki E, Campbell M, Doyle SL. Targeting the NLRP3 inflammasome in chronic inflammatory diseases: Current perspectives. J Inflamm Res 2015;8:15-27.

11) Menu P, Vince JE. The NLRP3 inflammasome in health and disease: The good, the bad and the ugly. Clin Exp Immunol 2011;166(1):1-15.

12) Mason DR, Beck PL, Muruve DA. Nucleotide-binding oligomerization domain-like receptors and inflammasomes in the pathogenesis of non-microbial inflammation and diseases. J Innate Immun 2012; 4(1):16-30.

13) Higaki $T$, Okano M, Fujiwara $T$, Makihara $S$, Kariya $S$, Noda $Y$, et al. COX/PGE(2) axis critically regulates effects of LPS on eosinophiliaassociated cytokine production in nasal polyps. Clin Exp Allergy 2012;42(8):1217-26

14) Okano M, Fujiwara $T$, Haruna $T$, Kariya $S$, Makihara $S$, Higaki $T$, et al. Prostaglandin E(2) suppresses staphylococcal enterotoxin-induced eosinophilia-associated cellular responses dominantly through an E-prostanoid 2-mediated pathway in nasal polyps. J Allergy Clin Immunol 2009;123(4):868-74.

15) Shen Y, Pan CK, Tang XY, Yang YC, Ke X, Kou W, et al. Significance of interleukin-17A in patients with nasal polyposis. Asian Pac J Allergy Immunol 2011;29(2):169-75.

16) Pawankar R. Nasal polyposis: An update: Editorial review. Curr Opin Allergy Clin Immunol 2003;3(1):1-6.

17) Månsson A, Bogefors J, Cervin A, Uddman R, Cardell LO. NODlike receptors in the human upper airways: A potential role in nasal polyposis. Allergy 2011;66(5):621-8. 
18) Zhang S, Liu Y, Shen C, Li G, Yang K, Shi X, et al. [The role of Nods like receptors in the patients with allergic rhinitis]. Lin Chung Er Bi Yan Hou Tou Jing Wai Ke Za Zhi 2015;29(15):1323-8.

19) Wan H, Su H, Wu Y, Zhao Y, Zhou M. [Expression and significance of NLRP3 inflammasome and its downstream factors IL-1 $\beta /$ IL-18 in rat model of allergic rhinitis]. Zhonghua Er Bi Yan Hou Tou Jing Wai Ke Za Zhi 2015;50(2):145-50.

20) Faner R, Sobradillo P, Noguera A, Gomez C, Cruz T, LópezGiraldo A, et al. The inflammasome pathway in stable COPD and acute exacerbations. ERJ Open Res 2016;2(3).

21) Bauernfeind FG, Horvath G, Stutz A, Alnemri ES, MacDonald K, Speert $\mathrm{D}$, et al. Cutting edge: NF-kappaB activating pattern recognition and cytokine receptors license NLRP3 inflammasome activation by regulating NLRP3 expression. J Immunol 2009;183(2):787-91.

22) Schroder K, Sagulenko V, Zamoshnikova A, Richards AA, Cridland JA, Irvine KM, et al. Acute lipopolysaccharide priming boosts inflammasome activation independently of inflammasome sensor induction. Immunobiology 2012;217(12):1325-9.

23) Stutz A, Golenbock DT, Latz E. Inflammasomes: Too big to miss. J Clin Invest 2009;119(12):3502-11.

24) Mariathasan S, Weiss DS, Newton K, McBride J, O'Rourke K, Roose-Girma M, et al. Cryopyrin activates the inflammasome in response to toxins and ATP. Nature 2006;440(7081):228-32.

25) Muñoz-Planillo R, Kuffa P, Martínez-Colón G, Smith BL, Rajendiran
TM, Núñez G. $\mathrm{K}^{+}$efflux is the common trigger of NLRP3 inflammasome activation by bacterial toxins and particulate matter. Immunity 2013;38(6):1142-53.

26) Shi J, Zhao Y, Wang Y, Gao W, Ding J, Li P, et al. Inflammatory caspases are innate immune receptors for intracellular LPS. Nature 2014;514(7521):187-92.

27) Zhao LR, Xing RL, Wang PM, Zhang NS, Yin SJ, Li XC, et al. NLRP1 and NLRP3 inflammasomes mediate LPS/ATP induced pyroptosis in knee osteoarthritis. Mol Med Rep 2018;17(4):5463-9.

28) Chen C, Ma X, Yang C, Nie W, Zhang J, Li H, et al. Hypoxia potentiates LPS-induced inflammatory response and increases cell death by promoting NLRP3 inflammasome activation in pancreatic $\beta$ cells. Biochem Biophys Res Commun 2018;495(4):2512-8.

29) Wang S, Zhang H, Xi Z, Huang J, Nie J, Zhou B, et al. Establishment of a mouse model of lipopolysaccharide-induced neutrophilic nasal polyps. Exp Ther Med 2017;14(6):5275-82.

30) Perregaux DG, McNiff P, Laliberte R, Hawryluk N, Peurano H, Stam E, et al. Identification and characterization of a novel class of interleukin-1 post-translational processing inhibitors. J Pharmacol Exp Ther 2001;299(1):187-97.

31) Lin H, Li Z, Lin D, Zheng C, Zhang W. Role of NLRP3 inflammasome in eosinophilic and non-eosinophilic chronic rhinosinusitis with nasal polyps. Inflammation 2016;39(6):2045-52 . 